\title{
LA CONFIGURACIÓN DE LA DIMENSIÓN DE LO POLIIIICO EN LAS NARRATIVAS POLIIIIICAS QUE CIRCULAN POR FACEBOOK EN EL CHACO
}

THE CONFIGURATION OF THE POLIIICAL DIMENSION IN THE NARRAIVES THAT CIRCULATE IN FACEBOOK WITHIN THE CONTEXT OF POLIIICS IN CHACO

Romina Gisel Gayoso 1/ Articulo recibido: 21 de junio 2020 - Articulo aprobado: 4 de noviembre 2020

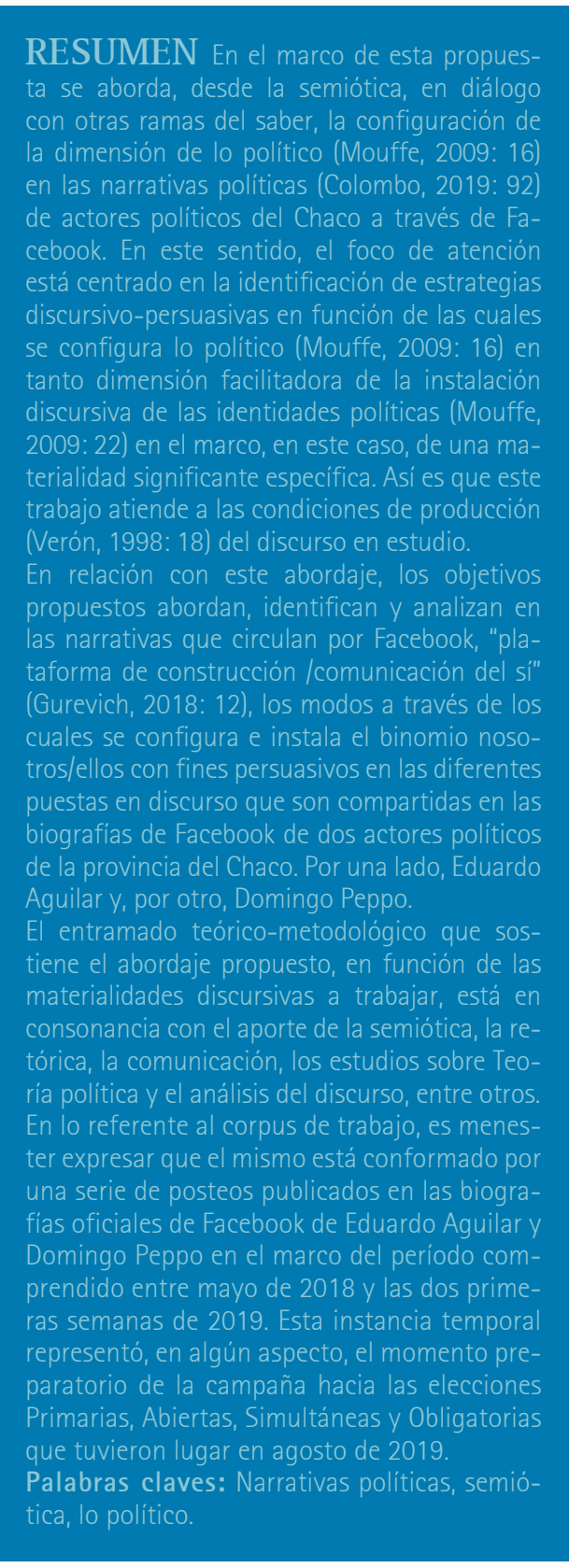

' Profesora y Licenciada en Letras, Departamento de Letras, Facultad de Humanidades, UNNE. Correo electrónico: rominitagayoso@gmail.com

\section{INTRODUCCIÓN}

El vínculo entre la esfera (Lotman, 1996: 35) de la comunicación y la de la política ha generado en esta zona del país nuevas formas de configuración de lo político (Mouffe, 2009: 16). En este sentido, se podría expresar que cobró relevancia, en algún aspecto, cierta espectacularización de la construcción y puesta en discurso de las identidades politicas (Mouffe, 2009: 22) de actores políticos chaqueños de primera línea que funcionan como representantes de diferentes espacios políticos, tanto tradicionales como el partido justicialista y el partido radical, como asi también emergentes, aquellos que proponen un posicionamiento político más amplio.

Estos nuevos modos de mediatización de la oposición nosotros/ ellos dan cuenta de la aparición de estrategias de persuasión que resultan innovadoras en esta parte de la Argentina. Se sostiene esto porque en estas latitudes la instalación de candidatos políticos y las instancias de persuasión estaban asociadas, antes de la aparición y uso recurrente de las redes sociales por parte de los ciudadanos chaqueños, al contacto cara a cara a través de reuniones y recorridas barriales entre otras acciones. Sin embargo, en la actualidad, mayoritariamente el contacto inicial entre los actores políticos y los ciudadanos-consumidores (Han, 2013: 56) se da a través de las diferentes redes sociales. Estas actúan como espacios semióticos-dinámicos de construcción, re-actualización, espectacularización y popularización constante del yo. En este sentido es que se transforman en el terreno ideal para la instalación persuasiva de las identidades de los actores políticos, puesto que en este espacio de interacción, simultáneo al "real", la continua exposición del actor político robustece su condición de sujeto de acción y por tanto contribuye, en algún aspecto, con su búsqueda constante de aceptación y, por ende, de captación de votos.

En este contexto de constante exposición del yo, el acto narrativo adquiere mayor preponderancia, puesto que como bien pondera Bruner (2013), la configuración de la identidad lleva implícito el acto de narrar debido a que el yo da a conocer, a través del relato, su experiencia de existir en comunidad. Este planteo a su vez coincide 
De Prácticas y discursos

Universidad Nacional del Nordeste

Centro de Estudios Sociales

Año 9, Número 14, 2020, Octubre

ISSN 2250-6942

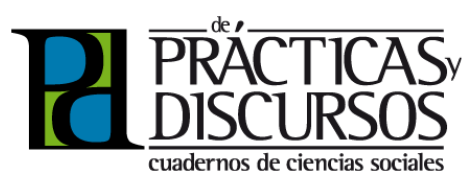

ABSTRACT In consonance with the field of Semiotics and other branches of knowledge, this framework proposes the configuration of the political dimension in narratives (Colombo, 2019; 92) used by political actors in Chaco via Facebook. In this sense, the framework focuses on how the political (Mouffe, 2009: 16) is configured as a dimension that facilitates the installation of political identities (Mouffe 2009: 22) within the context of a specific and significant political discourse implementation. In such respect, this work concentrates on the conditions of production (Verón, 1998: 18) of the discourse under study.

In terms of the approach described, this work aims to address, identify and analyze the ways in which the binomial we/they is configured and installed for persuasive purposes in the narratives used in the social media, particularly in Facebook, "plataforma de construcción/comunicación del si" (Gurevich, 2018: 12), which is one of the networking sites mostly used by politicians in Chaco during either election or non-election periods. The corpus analyzed is the discourse posted on each of their Facebook walls by two political leaders from Chaco: Eduardo Aguilar on the one hand, and Domingo Peppo on the other.

In addition, the development of this composition has been constructed upon a series of posts published on both Aguilar's and Peppo's official Facebook walls within the period ranging from December 2018 to the earliest two weeks of 2019. The importance of this time period lies on the fact that, to some extent this temporary instance represented the campaign preparation towards the election held in August 2019: the Primarias, Abiertas, Simultáneas y Obligatorias or PASO, which is an election prior to the general elections in Argentina. The theoretical-methodological framework of the proposed approach, in terms of the discursive corpus to analyze, is supported by the contribution of Semiotics, Rhetoric, Communication, studies on Political Theory and Discourse Analysis, among others.

Key Words: Political narratives, semiotics, the political. con la postura de Garcia (2004: 136), quien sostiene: "la narración es un dispositivo ritual-performativo" que facilitaría la expresión de las diferentes subjetividades en distintas dimensiones.

En esta oportunidad, la atención está centrada específicamente en las narrativas políticas (Colombo, 2019: 92). Estas inicialmente pueden ser entendidas como materialidades significantes en el marco de las cuales de forma polémica se instala la dimensión de lo político en diferentes contextos comunicacionales como, por ejemplo, las redes sociales. En este sentido, a continuación se aborda el caso Facebook.

\section{LAS REDES SOCIALES COMO DISCURSOS SOCIALES COMPLEJOS. EL CASO FACEBOOK}

Las redes sociales en general, y Facebook en particular, pueden ser entendidas, en términos de Angenot (2010: 45), como discursos sociales complejos, porque su lógica de generación de sentidos sienta sus bases en la confluencia de diferentes lenguajes- semiosis que configuran los modos de comunicar las historias que los usuarios quieren contar/exponer ante la comunidad virtual. En este sentido es que el diálogo (Bajtín, 1982: 190) entre lo simbólico, lo icónico y lo indicial adquiere un rol preponderante que facilita operaciones semióticas a través de la cuales se diseña aquel perfil que, en este caso, el candidato político intenta hacer legible, por tanto, comprensible y aceptado por los ciudadanos.

Además, esta posibilidad de comunicar/contar que ofrece a partir de la conjunción de estos modos de puesta en discurso es lo que acentúa lo complejo de su matriz comunicacional, a la vez que la posiciona de una manera diferente respecto de otras redes sociales, puesto que le otorga al usuario posibilidades diversas de expresar aquello que busca hacer visible.

Es decir, Facebook, en tanto herramienta de comunicación, ha sabido y sabe leer la lógica de la demanda comunicacional actual y en base a ello crea las condiciones necesarias para que los usuarios puedan solventar su necesidad de hacer saber quiénes son y qué hacen. En razón de ello, el espacio simbólico de la biografía de Facebook está configurado de tal manera que permite al usuario exponer, a través de una hibridación significante entre lo verbal y las imágenes, performances que funcionan como indices de aquello que busca instalar como verdad.

En la provincia del Chaco, dicha red social se ha posicionado 
De Prácticas y discursos

Universidad Nacional del Nordeste

Centro de Estudios Sociales

Año 9, Número 14, 2020, 0ctubre

ISSN 2250-6942
La configuración de la dimensión de lo político en las narrativas políticas que circulan por Facebook en el Chaco

The configuration of the political dimension in the narratives that circulate in Facebook within the context of politics in Chaco

como una de las más utilizadas por los candidatos chaqueños en el marco de las últimas elecciones (2015). Además, ha logrado instalarse en esta zona del país como un espacio semiótico en el que las identidades que alli se configuran adscriben a la lógica de una sociedad transparente. Es decir, un sitio (Han, 2014: 16) que facilita a los usuarios, a partir de una constante espectacularización, el posicionamiento de un tipo de identidad cimentado en un continuo hacer relacionado con los hábitos de esta región. Estas son algunas de las razones por las que se centra la atención esta red social y no en otras.

Asimismo, específicamente en el caso de los actores políticos, Facebook les ofrece la posibilidad de entablar un vínculo con sus posibles votantes a través de una constante exposición que habilita la potenciación de su capacidad de gestión. En este sentido, es que la espectacularización del yo que construyen y publicitan se transforma en una estrategia de persuasión pero, por sobre todas las cosas, funciona como un índice (Peirce, 1987: 56) de una puesta en acción de las subjetividades que da cuenta de una "especie de mutación histórica: un movimiento ligado de manera inextricable al capitalismo y a la cultura de masas..." (Sibilia, 2013: 303). Esta mutación posiciona a los sujetos en general, y a los actores políticos en particular, como objetos consumibles constantemente publicitados a través de las vidrieras transparentes que ofrecen estratégicamente las redes sociales como Facebook donde, según Han (2013: 98), "el consumidor compra lo que le gusta. Sigue sus inclinaciones individuales. Su divisa es me gusta". Signo icónico representativo de aceptabilidad o de indiferencia en la actual sociedad de la trasparencia (Han, 2013: 32). Este razonamiento puesto de manifiesto hasta aquí permitiría comprender que la configuración de las subjetividades contemporáneas atravesadas por la fuerza del mercado instalan al yo como el protagonista de los relatos que habitan el ágora digital (Han, 2013: 97). Específicamente, en el caso de los actores políticos, los posiciona como héroes/proveedores capaces de ofrecer las mejores ofertas para aquellas diversas demandas que buscan solventar los ciudadanos-consumidores (Han, 2013: 56).

Actualmente, las leyes de oferta y demanda, propias de la lógica del mercado, fijan hábitos y en relación con ello instalan creencias (Peirce, 1987: 45) en los sujetos a través de diferentes mecanismos de significación vinculados, en los tiempos que corren, con el carácter de veracidad que solo adquiere aquello que se expone. Esto último podría llevar a pensar que esa identidad 
De Prácticas y discursos

Universidad Nacional del Nordeste

Centro de Estudios Sociales

Año 9, Número 14, 2020, Octubre

ISSN 2250-6942

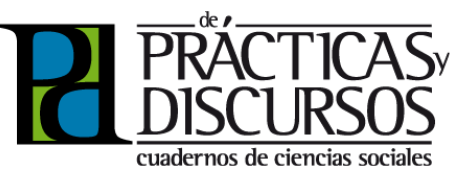

proactiva que busca instalar el actor político, en las narrativas que circulan por Facebook, reafirmaría su condición de mercancía. Una que en función de cómo se publicite podrá lograr, o no, persuadir a sus posibles votantes/compradores.

En este sentido, el continuo hacer que publicita el actor político a través de Facebook potenciaria la posibilidad de robustecer su capacidad de proveedor puesto que, como bien pondera Han (2013: 29), "en la sociedad expuesta, cada sujeto, es su propio objeto de publicidad. Todo se mide en su valor de exposición (...) El exceso de exposición hace de todo una mercancía (...)" factible, o no, de logar la aceptación de los ciudadanos-consumidores (Han, 2013: 56), siempre y cuando logre identificar las carencias de estos y convertirlas en oportunidades para la construcción de ofertas seductoras. La acción de narrar, en tanto acto performativo del yo, adquiere en este contexto transparente una gran importancia que, dependiendo de los modos en que se articula el relato, cuyo protagonista es el actor político, dependerán las posibilidades que este tenga de lograr persuadir a su electorado. En relación con esto, en el apartado siguiente se aborda el vínculo ente las narrativas políticas (Colombo, 2019: 92) y la configuración de la dimensión de lo político (Mouffe, 2009: 16) en el marco de Facebook.

\section{LAS NARRATIVAS POLITICAS COMO ESPACIO DE SENTIDO DONDE SE CONFIGURA LA DIMENSIÓN DE LO POLITICO}

Definir lo que se entiende por narrativas políticas (Colombo, 2019: 92) implica, en primer término, reflexionar sobre su configuración. Es decir, comprender cuál es su estructura y, en segundo término, entender qué finalidad comunicativa buscan concretar. En razón de estos interrogantes, se podría exponer, en términos de Colombo (2019: 89), que las mismas pueden ser concebidas como una puesta en discurso en el marco de la cual

los actores en tanto participantes del contexto de intercambios y de lucha entre enunciadores, insertos en el campo de lo politico 'hablan', 'cuentan algo' a través de sus perfiles de Facebook por lo que ponen de manifiesto sus voces y forman parte de una puesta en escena. Una estructura de la acción que los ubica en distintos roles: el candidato que defiende su posición y realiza las acciones; quien/es busca/n impedírselo o desacreditarlo y el tercero quien oficia de testigo de los hechos". (Colombo, 2019: 89) 
De Prácticas y discursos

Universidad Nacional del Nordeste

Centro de Estudios Sociales

Año 9, Número 14, 2020, 0ctubre

ISSN 2250-6942
La configuración de la dimensión de lo político en las narrativas políticas que circulan por Facebook en el Chaco

The configuration of the political dimension in the narratives that circulate in Facebook within the context of politics in Chaco

Es decir, funcionan como un espacio de significación que implica una dimensión polémica (Amossy, 2016: 26) atendiendo a que, como bien plantea Amossy (2016: 26), "la polémica se inscribe plenamente en la argumentación, en la medida en que esta ancla en la divergencia y la confrontación de puntos de vistas", tal y como lo propone este tipo de discurso, puesto que lo que hace es generar las condiciones, a través del relato, para la cristalización de la contienda entre sujetos de acción vinculados al ámbito político donde cada uno busca potenciar su propio yo en función de, por un lado, instalarse positivamente $y$, por otro, oponerse a la figura de su adversario político.

Todo lo mencionado potencia, además, el carácter persuasivo de las narrativas políticas ya que, al posibilitar la conformación discursiva de las identidades políticas (Mouffe, 2009: 22), funcionan como plataforma argumentativa para que los candidatos políticos intenten lograr la adhesión de los votantes. En este sentido, las narrativas políticas generan las condiciones para la puesta en discurso de diferentes argumentarios (Plantín, 2016: 69) que articulados entre sí permiten la orquestación de un relato convincente a través del cual el actor político busca reafirmar la aceptación de sus prodestinatarios (Verón, 1987: 14), como así también intenta revertir la postura de los contradestinatarios y, por sobre todo, lograr la aprobación de los paradestinatarios (Verón, 1987: 14). Aquellos que representan al sector social de los indecisos y al que, mayoritariamente, se direcciona la acción persuasiva.

Esta lógica discursiva que caracteriza a las narrativas políticas es por tanto la que facilita la instalación de lo político (Mouffe, 2009: 16), entendido como "la dimensión de antagonismo constitutiva de las sociedades humanas", porque genera las condiciones para la cristalización del juego de oposición nosotros/ ellos a partir del cual se facilita y legitima la lucha entre proyectos hegemónicos opuestos (Mouffe, 2009: 28). A su vez, estos proyectos, al oponerse entre sí, contribuyen, en algún aspecto, a mantener activa la naturaleza democrática de las sociedades actuales, a pesar de que por momentos ciertos sectores tienden a instalar lo que Mouffe (2009) entiende como pospolítica. Es decir, aquella forma de encarar la acción política a partir de la difuminación de las fronteras políticas, lo cual apuntaría a la instalación de un estado de consenso que disiparía todo disenso producto de la oposición nosotros/ellos, pero como bien resalta Mouffe (2009: 19), "lo político nunca puede ser erradicado 
De Prácticas y discursos

Universidad Nacional del Nordeste

Centro de Estudios Sociales

Año 9, Número 14, 2020, Octubre

ISSN 2250-6942

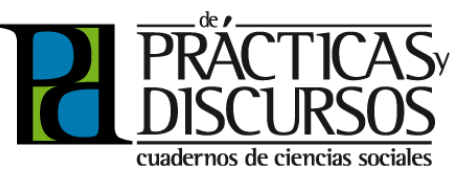

porque puede obtener su energía de las más diversas empresas humanas", asegurando así la potenciación del pluralismo.

El recorrido realizado hasta aquí permite, por tanto, solidificar la potencialidad de las narrativas políticas en tanto dispositivodiscursivo facilitador de la configuración, instalación y mediatización de lo político (Mouffe, 2009: 16) a partir de la activación de la dimensión polémica, en tanto instancia promotora de la oposición nosotros/ellos en términos persuasivos. En este sentido, y a los fines de profundizar en esto último, es que en el apartado siguiente la atención está centrada en el tratamiento de la configuración de lo político en relación con dos instancias: la de dicotomización y la de polarización (Amossy, 2016: 28), atendiendo a que estas se encuentran involucradas en toda construcción polémica del binomio nosotros/ellos.

\section{LA CONFIGURACIÓN POLÉMICA DE LO POLITICO EN LA RELACIÓN CON LAS INSTANCIAS DE DICOTOMIZACIÓN Y POLARIZACIÓN}

Tal y como se ha expuesto hasta el momento, las narrativas políticas funcionan como la superficie significante por excelencia para la puesta en discurso de lo político, es decir, de la cristalización de las identidades políticas (Mouffe, 2009: 22). Aquellas que implican para su configuración la presencia de una "exterioridad constitutiva" (Mouffe, 2009: 22), en otras palabras, un otro respecto del cual el yo busca diferenciarse. De este modo, se podría expresar, además, que toda identidad política es de indole relacional, puesto que implica la precondición de una diferencia para afirmar su propia potencialidad. Especificamente en el campo de lo político, toda construcción identitaria, al ser de indole polémica, implica una instancia de dicotomización, como así también de polarización (Amossy, 2016: 28). La relación entre estas instancias es la que permite sostener que en el ámbito de lo político el acto persuasivo surge en relación con el disenso.

La instancia de dicotomización, que implica toda puesta en acto de una configuración polémica, se orquesta en función de "dos oposiciones antitéticas que se excluyen mutuamente" (Amossy, 2016: 27) contribuyendo, de este modo, con la radicalización del debate. En este sentido, se podría expresar que esta instancia, en el campo de lo político, contribuye con el proceso de construcción y mediatización de toda identidad política, puesto que colabora con la instalación positiva del yo del actor político desde la singularidad 
De Prácticas y discursos

Universidad Nacional del Nordeste

Centro de Estudios Sociales

Año 9, Número 14, 2020, Octubre

ISSN 2250-6942
La configuración de la dimensión de lo político en las narrativas políticas que circulan por Facebook en el chaco

The configuration of the political dimension in the narratives that circulate in Facebook within the context of politics in Chaco
2 Posteo extraído de la biografía oficial de Facebook de Domingo Peppo el 22 de noviembre. Disponible en: https://www.facebook.com/ DomingoPeppo/?epa=SEARCH_BOX que lo caracteriza y que lo diferencia de sus adversarios políticos. Esto puede evidenciarse, por ejemplo, en el posteo realizado en la biografía oficial de Eduardo Aguilar el 18 de mayo de 2018. En dicho posteo, el enunciador expresa: "En 2019 voy a ser candidato a gobernador por un frente alternativo al de Peppo y Gustavo Martínez". Es decir, aqui el actor político articula su enunciado a partir del deíctico puro yo, a los fines de diferenciarse de sus oponentes, los cuales en este caso tienen nombre y apellido.

La instancia de polarización, por su parte, implica la efectivización, en términos de Amossy (2016: 28), de "agrupamientos en campos adversos: no es puramente de orden conceptual, sino social. En efecto, la polarización no solo representa una división en blanco/ negro, izquierda/derecha sino que plantea además un 'nosotros' frente a un 'ellos'". En otros términos, permite la vinculación estrecha entre el yo del actor político y su colectivo de representación. Esta vinculación termina de dar forma a la configuración de toda identidad política en tanto y cuanto pone de manifiesto la cristalización de reagrupamientos de identificación y la consolidación de determinada caracterización peyorativa de los otros, lo cual puede darse tanto de forma directa-explícita como indirecta-alegórica. En el posteo que aparece a continuación se puede apreciar cómo, en este caso, el nosotros es construido desde lo icónico y reforzado desde lo indicial a partir del gesto que realiza el grupo de actores sociales que rodean al, por aquel entonces, gobernador de la provincia del Chaco. Dicho gesto representa la $\mathrm{V}$ de la victoria, en tanto símbolo del peronismo e indicador de adscripción a un determinado posicionamiento político.

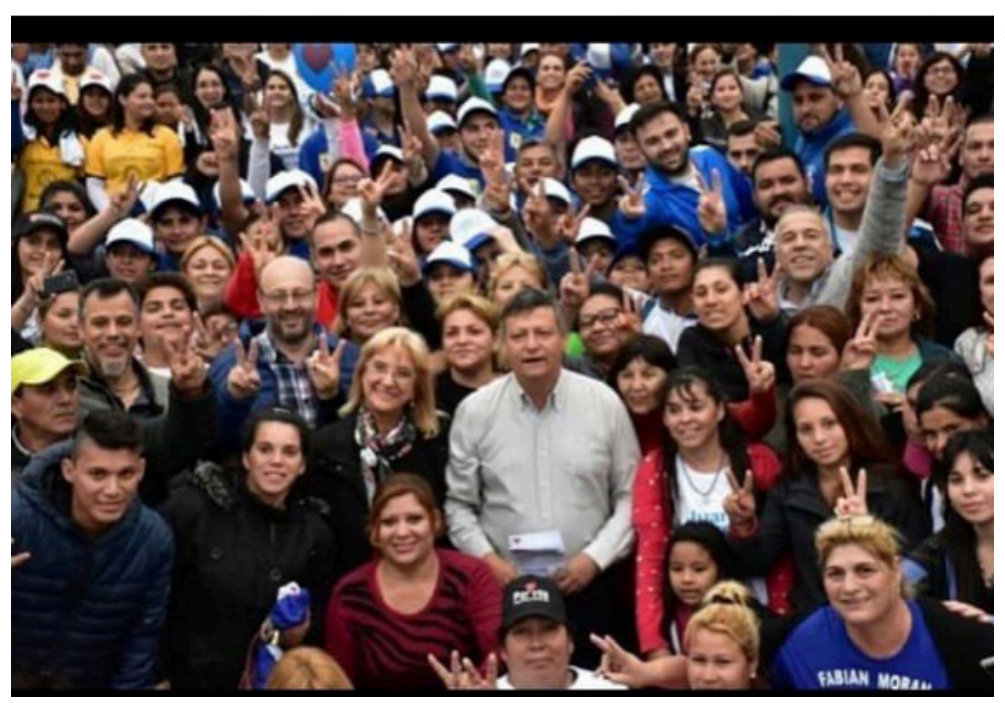


De Prácticas y discursos

Universidad Nacional del Nordeste

Centro de Estudios Sociales

Año 9, Número 14, 2020, Octubre

ISSN 2250-6942

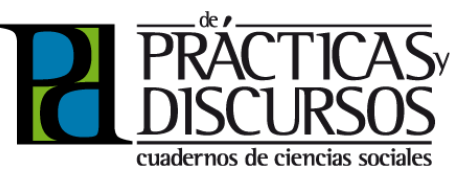

Sobre la base de todo lo expuesto hasta aquí, a continuación la atención estará centrada en el abordaje, identificación y contrastación de las estrategias discursivo-persuasivas puestas en práctica en las narrativas políticas, tanto de Eduardo Aguilar como así también de Domingo Peppo, al momento de configurar la dimensión de lo político. Para llevar a cabo esta acción, se trabaja con una serie de posteos compartidos en las biografías oficiales de estos actores políticos entre mayo de 2018 y las dos primeras semanas de 2019. Se decide centrar el foco de atención en este periodo porque el mismo representa la instancia electoral previa a las elecciones Primarias, Abiertas, Simultáneas y Obligatorias de 2019 en la provincia del Chaco.

LA CONFIGURACIÓN PERSUASIVA DE LO POLITICO EN LAS NARRATIVAS POLITICAS QUE CIRCULAN POR FACEBOOK

Los meses finales de 2018 y los iniciales de 2019 permitieron evidenciar de diferentes formas, y a través de los distintos medios de comunicación, la gestación de estrategias políticas destinadas a contribuir con la instalación de los posibles candidatos a la gobernación del Chaco. En este sentido, los diferentes espacios políticos promocionaban a sus representantes a los fines de, en algún aspecto, mediatizar procesualmente las distintas opciones en pugna por el poder. En este contexto, las narrativas políticas que circularon por Facebook se convirtieron en catalizadoras de expresión de aquellas contiendas políticas antecesoras de la campaña electoral vinculada con las elecciones Primarias, Abiertas, Simultáneas y Obligatorias que tendrian lugar en agosto de 2019.

En relación con lo mencionado, los modos a través de los cuales se configura discursivamente lo político en las narrativas tanto de Aguilar como así también de Peppo ponen de manifiesto la puesta en discurso de diferentes recursos persuasivos que dan cuenta, a su vez, de diferentes maneras de encarar la comunicación política en tiempos previos a la campaña vinculada con las elecciones Primarias, Abiertas, Simultáneas y Obligatorias.

En el caso específico de Eduardo Aguilar, se puede identificar que intenta inicialmente, en consonancia con la instancia de dicotomización (Amossy, 2016: 28), instalar un yo que busca configurarse a partir de valores morales entendidos por la comunidad como positivos. 
De Prácticas y discursos

Universidad Nacional del Nordeste

Centro de Estudios Sociales

Año 9, Número 14, 2020, Octubre

ISSN 2250-6942
La configuración de la dimensión de lo político en las narrativas políticas que circulan por Facebook en el chaco

The configuration of the political dimension in the narratives that circulate in Facebook within the context of politics in Chaco

\footnotetext{
${ }^{3}$ Posteo extraído del perfil oficial de Facebook del actual senador Eduardo Aguilar el 17 de octubre. Disponible en: https://www.facebook.com/EduardoAguilarChaco/
}

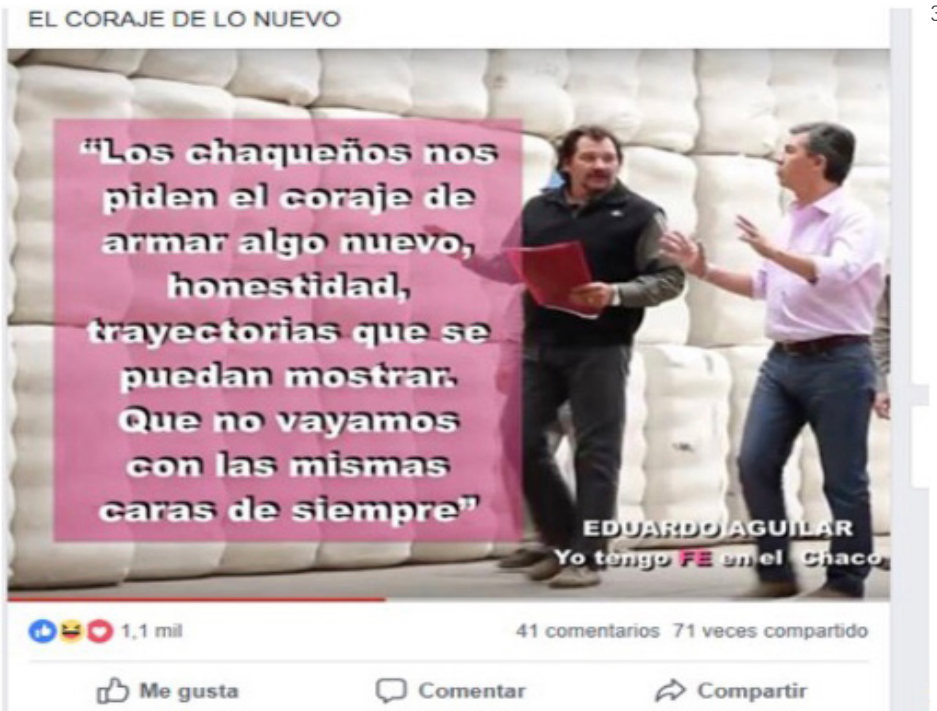

En el marco de los enunciados que conforman la red significante que configura al posteo arriba expuesto, se pueden evidenciar dos cuestiones que guardan relación entre sí. La primera tiene que ver con las características positivas que se buscan imprimir a la identidad del por aquel entonces senador Aguilar, y candidato a gobernador en 2019, a partir de aquellas demandas planteadas por los ciudadanos-consumidores (Han, 2013: 56). "Los chaqueños nos piden el coraje de armar algo nuevo; honestidad, trayectorias que se puedan mostrar". Tanto el lexema coraje como así también honestidad son expuestos como características que este actor político, que escucha a los ciudadanos, posee y que por tanto cargan de valor positivo a su etiqueta semántica.

La segunda cuestión que se puede analizar en este posteo tiene ver con el modo en que, una vez potenciado el yo de actor político, se busca consolidar el colectivo de representación a los fines de consolidar la oposición nosotros/ellos. En relación con esto se atina, en función de una construcción antitética, resaltar los valores positivos de Aguilar en oposición a los de sus adversarios políticos. Aquellos que aparecen configurados a través de la construcción "las mismas caras de siempre". Esta diferenciación construida discursivamente sirve como índice (Peirce, 1987: 68) de un modo de instalación de la instancia de polarización (Amossy, 2016: 28), a través de lo cual se orquesta la viabilidad de la figura de Aguilar en razón tanto de exaltar sus valores políticos como así también de mostrarlo como agente activo, siempre en movimiento y predispuesto al diálogo, tal como lo muestra la imagen. 


\footnotetext{
${ }^{4}$ Posteo extraído del perfil oficial de Facebook del actual senador Eduardo Aguilar el 22 de octubre. Disponible en: https://www.facebook.com/EduardoAguilarChaco/
}

Además, otra de las estrategias utilizadas en la narrativa política de Aguilar para solidificar su yo está relacionada con el modo en que plantea la oposición nosotros/ellos en función del binomio aptitud política/ineptitud política.

POR FIN LOS MEDIOS HABLAN

El enorme desmanejo que sufren Sámeep y sus trabajadores, que desfinancia a los jubilados del Inssep y endeuda a la provincia, tiene responsables directos e indirectos. El chancho y quienes lo engordaron con alianzas políticas

La primera vez que lo enfrenté generó un piquete de camiones estatales frente a la Plaza. Las otras veces me costó candidaturas a intendencia y gobernación. Sabido era que conmigo no había pactos.

Desde 2007 vengo enfrentando a esta forma de hacer política, admito que sin lograr una opción mayoritaria dentro del peronismo

En 2019 lo vamos a enfrentar desde un nuevo Frente, sumando a todos los chaqueños, peronistas, radicales e independientes, que quieren luchar en serio contra la pobreza y terminar con el acomodo, el clientelismo y la explotación electoral de las cajas públicas.

No elijo caminos fáciles. No pacto con quienes destruyen el Estado

CO Magda Monje y 950 personas más 135 comentarios 164 veces compartido

น Me gusta

$\square$ Comentar

$\Rightarrow$ Compartir

Este segundo posteo permite evidenciar, en primer lugar, el planteo de una orquestación discursiva a partir del uso de una metáfora en función de la cual se carga de valor negativo el yo de los adversarios políticos de Aguilar. Aquellos a quienes se responsabiliza de acciones que perjudican a diferentes sectores de la ciudadanía chaqueña.

En segundo lugar, y a los fines de continuar potenciando la dimensión de lo político, se recurre, en el marco del mismo posteo, a la utilización de la estrategia de enumeración. Dicho recurso es utilizado a los fines de solidificar la ineptitud política de los adversarios de Aguilar. Aquellos que generaron acciones perjudiciales (piquetes de camiones estatales frente a la plaza, imposibilidad de acceder a diferentes candidaturas).

En tercer lugar, y sobre la base de esta instalación del yo apto y activo de Aguilar, opuesto al de sus oponentes, se busca reforzar este perfil de sujeto de acción reafirmándolo en el discurso como un héroe. Uno que está dispuesto a luchar y a combatir contra las adversidades. En relación con esto, el uso del verbo "enfrentar", utilizado en la primera persona del pretérito perfecto simple, funciona como signo reforzador de este perfil de sujeto positivo. Estos recursos identificados hasta el momento, y en función de 
De Prácticas y discursos

Universidad Nacional del Nordeste

Centro de Estudios Sociales

Año 9, Número 14, 2020, Octubre

ISSN 2250-6942
La configuración de la dimensión de lo político en las narrativas políticas que circulan por Facebook en el chaco

The configuration of the political dimension in the narratives that circulate in Facebook within the context of politics in Chaco
${ }^{5}$ Posteo extraído del perfil de Facebook de Domingo Peppo el 22 de noviembre. Disponible en: https://www. facebook.com/DomingoPeppo/?epa=SEARCH_BOX los cuales se configura la dimensión de lo político (Mouffe, 2009: 16) en la narrativa de Aguilar, dan cuenta de un tipo de argumentario (Plantín, 2016: 69) que permite consolidar el carácter persuasivo de este discurso por medio del cual se busca tanto reforzar la credibilidad del colectivo de representación, al cual hace referencia por medio del uso del nosotros inclusivo, como así también de los indecisos.

La narrativa de Domingo Peppo, a diferencia de la de Eduardo Aguilar, adquiere otros matices discursivos en función del modo en que plantea la dimensión de lo político (Mouffe, 2009: 16) tal y como se verá a continuación.

\section{(7) Domingo Peppo}

22 de noviembre a las 12:30 - 6

Ayer en Bs.As., nos reunimos once referentes peronistas en búsqueda de construir una altemativa federal que resuelva los problemas que aquejan al pais.

Buscamos formar un \#peronismo transparente y concreto, con vocación frentista, que genere desarrollo \#federal y equitativo para el país, con opciones claras y superadoras.

Queremos sumar a todos los sectores y que cada uno esté representado y sea parte de esta propuesta de \#futuro, porque en definitiva queremos diversidad de un espacio que tiene heterogeneidad y eso hace a la riqueza del peronismo.

Necesitamos marcar un nuevo camino, es nuestra prioridad y por ello trabajamos.

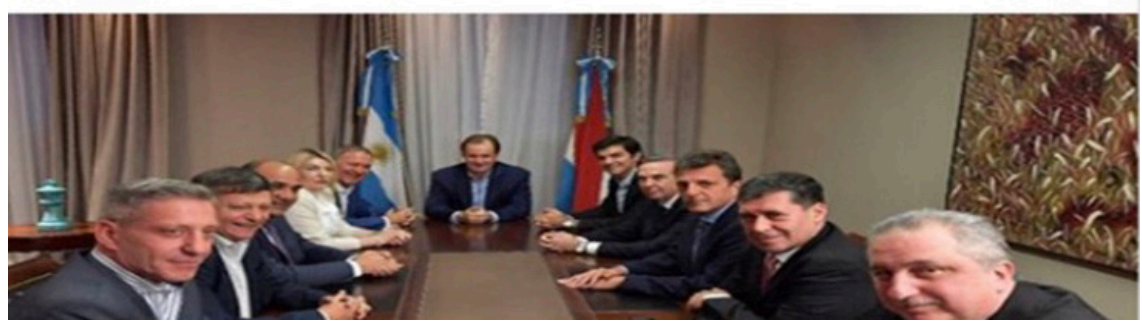

Especificamente, en este posteo se puede identificar, desde el inicio, que el yo de Peppo se busca consolidar positivamente en función de mostrarlo como un sujeto de acción integrado a un colectivo de identificación (Verón 1987: 35) específico: "los peronistas que buscan una alternativa federal". Es decir, aquellos sujetos/héroes que trabajan por un peronismo con características positivas, como la transparencia, y que no construyen un adversario determinado.

En relación con esto, se puede interpretar que la estrategia de persuasión de Domingo Peppo, por un lado, sienta sus bases en comunicar las cualidades positivas de ese colectivo del que es parte $y$, por otro, en omitir cualquier referencia a un posible adversario político. Esto permitiría interpretar que, en algún aspecto, el modo a través del cual se busca configurar 
De Prácticas y discursos

Universidad Nacional del Nordeste

Centro de Estudios Sociales

Año 9, Número 14, 2020, Octubre

ISSN 2250-6942
${ }^{6}$ Posteo extraído del perfil de Facebook de Domingo Peppo el 4 de noviembre. Disponible en: https://www. facebook.com/DomingoPeppo/?epa=SEARCH_BOX la identidad política de este candidato estaría en consonancia con aquel modelo político vinculado con lo que Mouffe (2009) denomina como la pospolítica.

Además, se puede mencionar que, a diferencia de la narrativa politica de Eduardo Aguilar, en la de Peppo se buscó potenciar su yo en función de la instalación y mediatización del perfil de un hombre común y padre de familia. Todo esto, a partir de la espectacularización de la intimidad de su vida familiar.

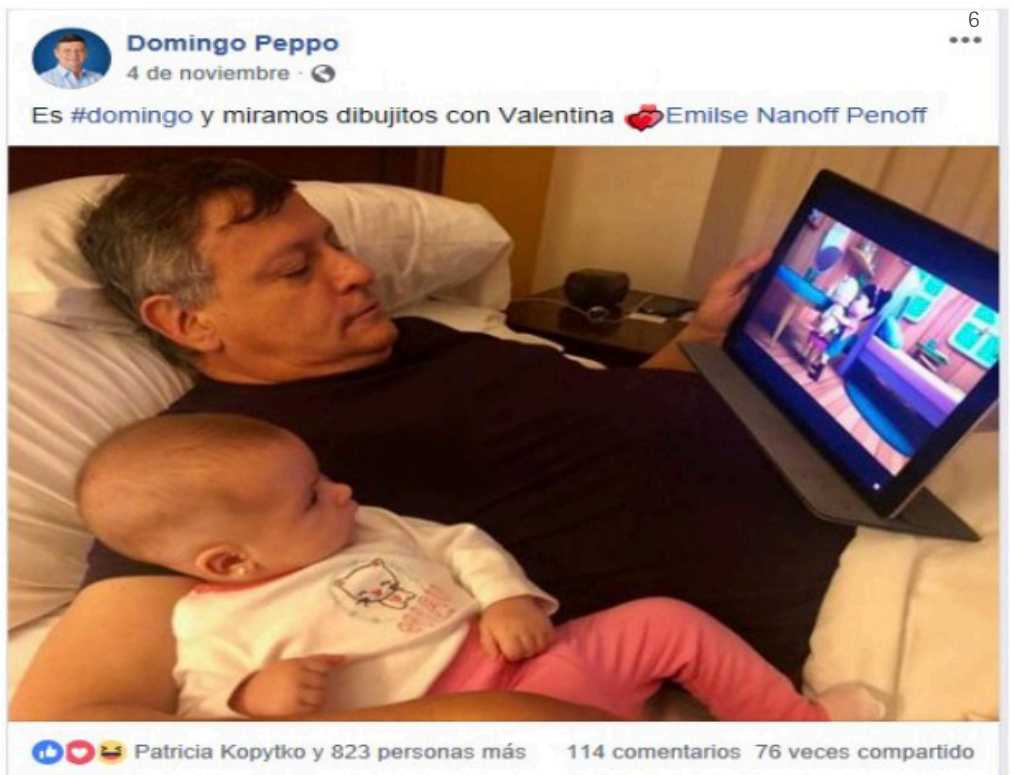

La estrategia de apertura del mundo privado (de lo corporal, la intimidad, el hogar, los afectos, tradicionalmente ocultos) hacia lo público refuerza la intención persuasiva acerca del carácter humano y cercano del actor político. En este sentido, y atendiendo al razonamiento de Arendt (2009: 59), quien expresa que lo público es aquello que "puede verlo y oírlo todo el mundo y tiene la más amplia publicidad posible", se podría sostener que, en este caso, la exposición de la intimidad familiar consolida el acto publicitario positivo del yo que busca instalar Peppo.

La identificación de los recursos discursivo-persuasivos en función de los cuales se orquestan las narrativas políticas abordadas permitiría expresar que ambos actores políticos construyen sus identidades políticas (Mouffe, 2009: 22) en función de argumentos tanto de orden simbólico-verbal como así también icónico, a través de los cuales buscan potenciar su perfil de sujeto de acción. Además, esta configuración identitaria puesta en discurso a par- 
De Prácticas y discursos

Universidad Nacional del Nordeste

Centro de Estudios Sociales

Año 9, Número 14, 2020, Octubre

ISSN 2250-6942
La configuración de la dimensión de lo político en las narrativas políticas que circulan por Facebook en el chaco

The configuration of the political dimension in the narratives that circulate in Facebook within the context of politics in Chaco
7 Posteos extraídos de los perfiles de Facebook de Domingo Peppo y Eduardo Aguilar el 10 de octubre. Disponibles en: https://www.facebook.com/ DomingoPeppo/?epa=SEARCH_BOX https://www.facebook.com/EduardoAguilarChaco/ tir del juego de inter-semiosis refuerza, en algún aspecto, una relación intertextual-interdiscursiva (Angenot, 2010: 45) pasado/presente en función de la cual se busca consolidar persuasivamente el posicionamiento enunciativo-político desde el cual cada actor político asume su voz. Específicamente, este tipo de relación pasado/presente se cristaliza en las narrativas abordadas a partir de un núcleo semántico relacionado con la activación social de la memoria (Ricoeur, 2008: 33).
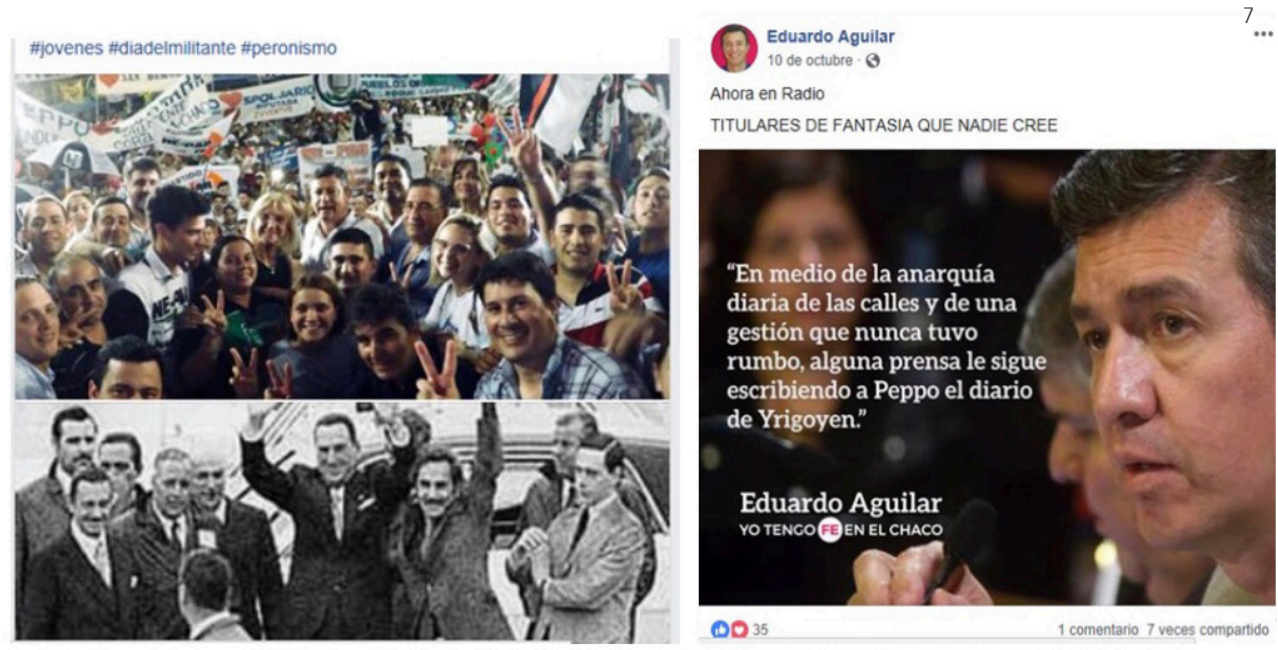

En el caso del primer posteo, se puede identificar que desde lo icónico se establece un diálogo (Bajtín, 1982: 190) entre el momento en que Domingo Peppo, en el marco de un acto político, expresa, por primera vez, su intención de volver a postularse como candidato a gobernador del Chaco en 2019 y la vuelta de Domingo Perón a la Argentina el 20 de junio de 1973. A través de este juego intertextual-interdiscursivo, se buscaria reforzar el yo positivo de Peppo, ante su prodestinatario (Verón, 1987: 14), en función de instalarlo, discursivamente, como el sucesor, en la provincia, de Perón. Por tanto, podría pensarse que esta estrategia busca acentuar una similitud positiva entre Perón y Peppo. En el caso del posteo extraído de la biografía de Facebook del por aquel entonces senador Eduardo Aguilar, y candidato a gobernador en 2019, se puede evidenciar que la relación dialógica pasado/presente es utilizada para reforzar el perfil negativo de su adversario político a partir de la vinculación, de indole negativa, que se establece entre la leyenda popular del diario del presidente Yrigoyen y el modo de comunicar de los medios hegemónicos de la provincia del Chaco, en relación con la actitud del 
De Prácticas y discursos

Universidad Nacional del Nordeste

Centro de Estudios Sociales

Año 9, Número 14, 2020, Octubre

ISSN 2250-6942

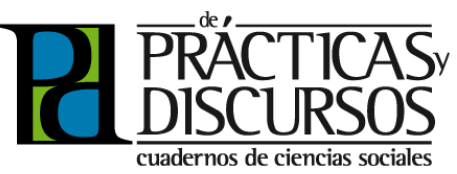

por aquel entonces gobernador Domingo Peppo. Es decir, aquí la relación dialógica adquiere un carácter de denuncia y, en este sentido, funciona como una herramienta más para reforzar la polarización propia de la construcción polémica de lo político que propone la narrativa política de Aguilar.

De este modo, el abordaje analítico llevado adelante a lo largo de este trabajo permitió evidenciar que las narrativas políticas representan un tipo de puesta en discurso que permite evidenciar distintos modos de orquestar persuasivamente la dimensión de lo político en relación con los diferentes intereses de los actores políticos tanto en instancias electorales como no electorales.

\section{CONCLUSIÓN}

A modo de cierre parcial, se puede expresar, en primer término, que las narrativas políticas pueden ser entendidas como un tipo de dispositivo que facilita la configuración y mediatización de las identidades políticas desde un punto de vista polémico, puesto que contribuyen con la instalación de lo político con fines persuasivos en diferentes contextos comunicacionales como, por ejemplo, Facebook. Espacio donde las acciones de narrar y compartir posibilitan la popularización del yo.

En segundo término, y en relación específica con las narrativas políticas abordadas, es menester exponer que cada una de estas demuestra la puesta en discurso de diferentes estrategias discursivo-persuasivas a los fines de potenciar el yo del actor político en relación con su colectivo de representación y en oposición a la/s figura/s de su/s adversario/s político/s. En este sentido, por ejemplo, la narrativa política de Eduardo Aguilar buscó solidificar la figura de este actor político en función, por un lado, de resaltar caracteristicas positivas de su yo y, por otro, de contraponerlo constantemente a la figura de su adversario político. En otras palabras, la narrativa política de Eduardo Aguilar da cuenta de una construcción polémica de la dimensión de lo político.

La narrativa política de Peppo, en cambio, centró su atención en la figura del actor político y buscó potenciarlo en función de mostrarlo cercano al pueblo, preocupado por instalarse como un líder dentro del partido justicialista chaqueño y un padre de familia que disfruta de compartir momentos con su hija pequeña. En este sentido, se podría comunicar que la narrativa política de Peppo en tiempos previos a las elecciones Primarias, Abier- 
De Prácticas y discursos

Universidad Nacional del Nordeste

Centro de Estudios Sociales

Año 9, Número 14, 2020, octubre

ISSN 2250-6942
La configuración de la dimensión de lo político en las narrativas políticas que circulan por Facebook en el Chaco

The configuration of the political dimension in the narratives that circulate in Facebook within the context of politics in chaco

tas, Simultáneas y Obligatorias no apostaba a una construcción de lo político en términos polémicos, sino que más bien estaba en consonancia con una postura cercana a lo denominado por Mouffe (2009) como pospolítica.

BIBLIOGRAFIA

AMOSSY, R. (2016). Apología de la polémica. Buenos Aires: Prometeo Libros.

ANGENOT, M. (2010). El discurso social. Los límites de lo pensable y lo decible. Buenos Aires: Siglo XXI editores.

ARENDT, H. (2009). La condición humana. Buenos Aires: Paidós.

BAJTíN, M. (1982). Estética de la creación verbal. Buenos Aires: Siglo Veintiuno.

COLOMBO, N. (2019). Narrar a través de las imágenes: algunas reflexiones sobre semiosis, narrativa y lo político en relación con el uso de las redes sociales. Revista Chilena de Semiótica, 11, 84-100. Publicación científica de la Asociación Chilena de Semiótica- ISSN-0717-3075. Disponible en: file:///C:/Users/romin/ Documents/SEMIÓTICA/SEMIÓTICA\%202019/Revista\%20Chilena\%20de\%20Semiótica-11-final-5.pdf

GARCíA, M. (2004). Narración, semiosis/memoria. Posadas: Editorial Universitaria.

GUREVICH, A. (2018). La vida digital. Intersubjetividad en tiempos de plataformas sociales. Buenos Aires: La Crujía.

HAN, B. CH. (2013). La sociedad de la transparencia. Barcelona: Herder.

MOUFFE, CH. (2009). En torno a lo político. Buenos Aires: Fondo de Cultura Económica.

PEIRCE, CH. (1987). Obra Lógica-semiótica. Madrid: Taurus.

PLANTíN, CH. (2016). La palabra polémica. Buenos Aires: Prometeo Libros. 
RICOEUR, P. (2008). La memoria, la historia, el olvido. Buenos Aires: Fondo de Cultura Económica.

SIBILIA, P. (2013). La intimidad como espectáculo. Buenos Aires: Fondo de Cultura Económica.

SLIMOVICH, A. (2017). La ruta a la presidencia argentina. Un análisis político e hipermediático de los discursos de Mauricio Macri en las redes sociales. Dixit [online], 26, 24-43. Disponible en: http://www.scielo.edu.uy/scielo.php?script=sci_ arttext\&pid=S0797-36912017000100024\&t|ng=es\&nrm=iso. ISSN 1688-3497. http://dx.doi.org/10.22235/d.v0i26.1321

VERÓN, E. (1987). El discurso político. Lenguajes y acontecimientos. Buenos Aires: Hachette.

(1998). La semiosis social. Fragmentos de una teoría de la discursividad. Buenos Aires: Gedisa. 